\title{
Coulisses
}

Revue de théâtre

13 | Hiver 1996

Varia

\section{Compte-rendu de la table ronde sur la mise en scène de la pièce}

\section{Thierry Miguet}

\section{(2) OpenEdition}

1 Journals

Édition électronique

URL : http://journals.openedition.org/coulisses/4143

DOI : $10.4000 /$ coulisses.4143

ISSN : 2546-9460

\section{Éditeur}

Presses universitaires de Franche-Comté

\section{Édition imprimée}

Date de publication : 1 janvier 1996

Pagination : 54-55

ISSN : 1150-594X

\section{Référence électronique}

Thierry Miguet, «Compte-rendu de la table ronde sur la mise en scène de la pièce », Coulisses [En ligne], 13 | Hiver 1996, mis en ligne le 15 mars 2019, consulté le 04 octobre 2020. URL : http:// journals.openedition.org/coulisses/4143; DOI : https://doi.org/10.4000/coulisses.4143

Ce document a été généré automatiquement le 4 octobre 2020.

Coulisses 


\title{
Compte-rendu de la table ronde sur la mise en scène de la pièce
}

\author{
Thierry Miguet
}

Séance présidée par Marie Miguet-Ollagnier, le Vendredi 24 Novembre 1995, de 17h45 à 18h15, dans la salle Georges Fourrier (Faculté des Lettres) à l'occasion du colloque Mythologie de la rébellion dans le théâtre 1890-1910. Avec également Lucile Garbagnati, responsable de la dramaturgie de cette pièce, et Joseph Melcore, auteur de sa mise en scène, et les acteurs.

\section{Ouverture de séance ${ }^{1}$}

1 Marie Miguet-ollagnier ouvre la séance en félicitant vivement les organisateurs et les acteurs de ce spectacle, qui a procuré aux spectateurs un très vif plaisir. A tout point de vue cette représentation lui semble une parfaite réussite. Elle approuve, en particulier, le côté « carnavalesque » de la mise en scène.

\section{Le choix de la pièce}

2 Lucile Garbagnati : Il était impossible de créer Juan José, œuvre longue et requérant de nombreux interprètes; les répétitions devaient s'effectuer pendant les mois d'été, avec des étudiants disponibles durant les grandes vacances. La proposition de Gérard Brey, à savoir L'Épidémie d'Octave Mirbeau, texte court avec une distribution restreinte, neuf rôles en principe, pouvant se ramener sans difficulté à sept personnages, a donc été la bienvenue.

\section{Le parti pris de la mise en scène}

3 Philippe Baron, professeur de littérature : le grossissement clownesque de la mise en scène renforce la puissance comique du texte. Sa nécessité, est apparue d'emblée à Joseph Melcore : donner du mouvement et des « images » à une œuvre trop statique et 
déclamatoire. Sept personnages pérorant derrière une table, cela n'était pas possible. La grande invention vivifiante fut alors celle des nez : Sabine Abrassard ${ }^{2}$ en fit un grand nombre et chaque acteur choisit le sien. Ensuite tout son personnage fut composé en fonction de son nez, de sa corpulence, son élocution, sa gestuelle.

«Le masque apporte un dynamisme à la pièce. La pièce explose. Le texte est animé par l'image. »

C'est dans cet esprit que le chant de «La Madelon »- anachronique, mais cela est sans importance - est ajouté au texte. Nouvelle explosion de joie, fidèle à l'esprit plus qu'à la lettre de l'auteur.

A l'époque de sa parution, de la première représentation (théâtre Antoine 29 avril 1898) la pièce était jouée "au pied de la lettre». Le public alors était plus sensible à la pertinence des discours. Mirbeau illustre par son œuvre le théâtre de la dérision. C'est le servir que de l'animer.

Marcelle Diaz Rozzotto remarque qu'il y a dans cette pièce une teinte de comedia dell'arte que la mise en scène choisie accentue avec bonheur. Le contenu est dur, mais la façon de jouer prend le parti d'en rire.

Joseph Melcore insiste sur l'importance de l'utilisation de l'espace et des accessoires disponibles. La table est renversée à un moment donné. Elle sert d'estrade aux proclamations du médecin, le docteur Triceps. Le rideau permet « une panoplie de corps sans bustes », qui remplace "les bustes de la République » mentionnés par la didascalie.

\section{Diction et expressivité}

6 Eva Montoya estime que tout est parfait dans ce spectacle, excepté la diction des acteurs, trop uniforme et vociférante à son goût. Réponse de Lucile Garbagnati, Joseph Melcore et Marjorie Moulet : d'une part, la voix de chaque acteur (et à la rigueur, son accent) a été respectée. Le maire a proféré ses dires avec des intonations différentes, avec des modulations. Les autres personnages, astreints davantage à un parler en accord avec leur nez, ne pouvaient pas, en plus, exercer des variations d'élocution.

Le rythme assez endiablé de la mise en scène obligeait l'ensemble des interprètes à hausser le ton assez généralement. Cependant le membre de l'opposition a pu, lui aussi, moduler sa voix et changer de registre. D'une manière globale, l'effort consistant à parler artificiellement selon le rôle empêchait la réalisation d'un second effort de modulation et de variété.

\section{Didascalie et interprétation}

Thierry Miguet: la «procession» en l'honneur du «bourgeois inconnu», Joseph, avec les trois coupes enflammées, correspond-elle à une indication de régie de Mirbeau lui-même?

Joseph Melcore: Mirbeau demandait la présence d'une cheminée où l'on brûlait la lettre annonçant la mort du bourgeois.

7 En l'absence de cheminée, il a fallu inventer un substitut. Ce fut la coupe, la première coupe, où la lettre fatale, allumée, se consume. Puis, toujours pour dynamiser la représentation (mais aussi pour obéir à toutes sortes d'indications de l'auteur, énonçant l'idée d'honneurs funéraires rendus au bourgeois inconnu, d'une sorte de 
rêve de grandeur bourgeoise) vint la "mise en scène" de deux autres coupes enflammées, avec cortège solennel.

8 C'était la réalisation, sur un pas de danse, des aspirations grandioses et dérisoires de la classe privilégiée. Avec un peu de chance, c'est la première coupe, la seule à contenir cette lettre annonçant le trépas de " Joseph ", qui s'éteint la dernière.

Bref, toutes les « inventions » de la mise en scène étaient en fait des fidélités créatrices, des écarts apparents, servant de valeur scénique et dramatique, et même idéologique de l'œuvre, pour la plus grande délectation des spectateurs.

\section{NOTES}

1. Les titres, intertitres et notes sont de la rédaction

2. Plasticienne, formée à l'École des Arts Décoratifs à Paris. Sabine Abrassard anime des ateliers d'arts plastiques. Elle participe aux créations du TUFC en élaborant des masques. 